\title{
The impact of COVID-19 on the plastic surgery activity in a high-complexity university hospital in Brazil: the importance of reconstructive plastic surgery during the pandemic
}

\author{
Vitor Penteado Figueiredo Pagotto ${ }^{1}$ (D) - Laielly Abbas ${ }^{1} \cdot$ Dov Charles Goldenberg $^{1} \cdot$ Rodolfo Costa Lobato $^{1}$. \\ Bruno Baptista do Nascimento ${ }^{1}$. Gustavo Gomes Ribeiro Monteiro ${ }^{1}$. Cristina Pires Camargo ${ }^{1}$. \\ Fabio de Freitas Busnardo ${ }^{1}$. Rolf Gemperli ${ }^{1}$
}

Received: 17 July 2020 / Accepted: 13 August 2020 / Published online: 21 August 2020

(C) Springer-Verlag GmbH Germany, part of Springer Nature 2020

\begin{abstract}
Background The Hospital das Clínicas - University of Sao Paulo Medical School (HCFMUSP) is the largest university hospital complex in Brazil. HCFMUSP has been converted into a reference center for coronavirus disease 2019. The Division of Plastic Surgery postponed non-essential surgeries and outpatient consultations, accomplishing new guidelines (ANG) of national and international organizations. Even with these challenges arising from the pandemic, alternatives were considered to maintain institutional characteristics. This study aims to analyze this new scenario and the impact on patients' assistance and Plastic Surgery residents training.

Methods Total number of surgeries, type of procedures, and outpatient consultations in 2020, before (pre-ANG) and after (postANG) ANG, were compared with the same period in 2019 (2019-pre and 2020-post).

Results A marked reduction in the total number of surgeries and outpatient consultations was observed in the post-ANG period. In the post-ANG period, 267 operations were performed (26.7 $\pm 20.3 /$ week), while in the 2019-post period, 1036 surgeries were performed $(103.6 \pm 9.7 /$ week $)(p=0.0002)$. Similarly, 1571 consultations were conducted in the post-ANG period $(157.1 \pm 93.6 /$ week), while in the 2019-post period, 3907 were performed (390.7 $\pm 43.1 /$ week) $(p=0.0003)$. However, in the post-ANG period, an increase in the proportion of reconstructive compared with aesthetic surgery was observed. The maintenance of highly complex procedures such as microsurgical transplants was also identified.

Conclusions The predominant profile of reconstructive surgeries at the Division of Plastic Surgery allowed the continuity of procedures at all technical complexity levels, patient care maintenance, and Plastic Surgery residents training.

Level of evidence: not ratable
\end{abstract}

Keywords Plastic Surgery $\cdot$ Reconstructive surgical procedures $\cdot$ Coronavirus $\cdot$ Pandemics $\cdot$ Teaching Hospitals

\section{Introduction}

Coronaviruses are agents responsible for human emerging and reemerging infection [1]. At the end of 2019, a new pathogen

Vitor Penteado Figueiredo Pagotto

vitorpfpagotto@gmail.com

1 Hospital das Clínicas, University of Sao Paulo Medical School, Rua Dr. Ovídio Pires de Campos, 225, São Paulo, São Paulo 05403-010, Brazil subtype was discovered as causing a pneumonia outbreak in Wuhan, China. The occurrence of this event was broadcast by the World Health Organization (WHO) for the first time on January 4, 2020. Nine days later, the first case of the disease outside the country of origin was reported in Taiwan. On March 11, 2020, the worldwide spread of the disease was characterized as a pandemic by the WHO [2].

The confirmation of the first case in Brazil occurred on February 26, 2020. On the date of this publication (June 19, 2020), 978,142 cases have been confirmed, as well as 47,748 deaths [3]. The Greater São Paulo, which is the most populous 
region in the country with approximately 21.6 million inhabitants, was also the main affected area [4]. To date, 192,628 cases and 11,846 deaths have been recorded [3].

The Hospital das Clínicas - University of São Paulo Medical School (HCFMUSP), which is the largest university hospital complex in the country, has been converted into a reference center for the treatment of coronavirus disease 2019 (COVID-19) [5]. An entire building with 200 intensive care unit beds (ICU), recently expanded to 350 ICU out of its 918 total capacity, was remodeled to admit only patients with COVID-19.

Almost all medical specialties adapted their routine to face the COVID-19 challenge. The Division of Plastic Surgery, following the national and international organizations' recommendations, and the guidelines of our Institutional Crisis Committee, postponed non-essential surgeries and outpatient consultations [6, 7]. One of the main reasons for delaying elective procedures is the known risk of post-operative complications and worse prognosis of patients acquiring COVID19 [8]. Even with these challenges arising from the pandemic, alternatives were considered to maintain institutional characteristics.

HCFMUSP mission is to be an institution of excellence, recognized nationally and internationally in teaching, research, and assistance. Even during this unexpected change in medical activity, the concern about practice training could not be disregarded. The medical staff was also reorganized to offer support and teaching for residents. This aim of this study is to analyze this new scenario and the impact of changes in plastic surgery assistance and medical training.

\section{Methods}

A time frame of 10 weeks, before and after the accomplishment of new guidelines (ANG) for maintaining only essential activities, was considered. The total number of surgeries was evaluated, comparing the periods of January-March 2020 (pre-ANG) and March-May 2020 (post-ANG) with similar periods in 2019 (named 2019-pre- and 2019-post, respectively). Also, the type of procedure and the number of outpatient consultations were evaluated. Operational activities during the 2020 pandemic were also analyzed according to the facility (in the high-exposure building dedicated to the care of patients with COVID-19 or in all other low-exposure units).

The pre-ANG period was from January 6 to March 15 , 2020, while post-ANG was from March 16 to May 24, 2020. The year 2019 was used as the control, comparing

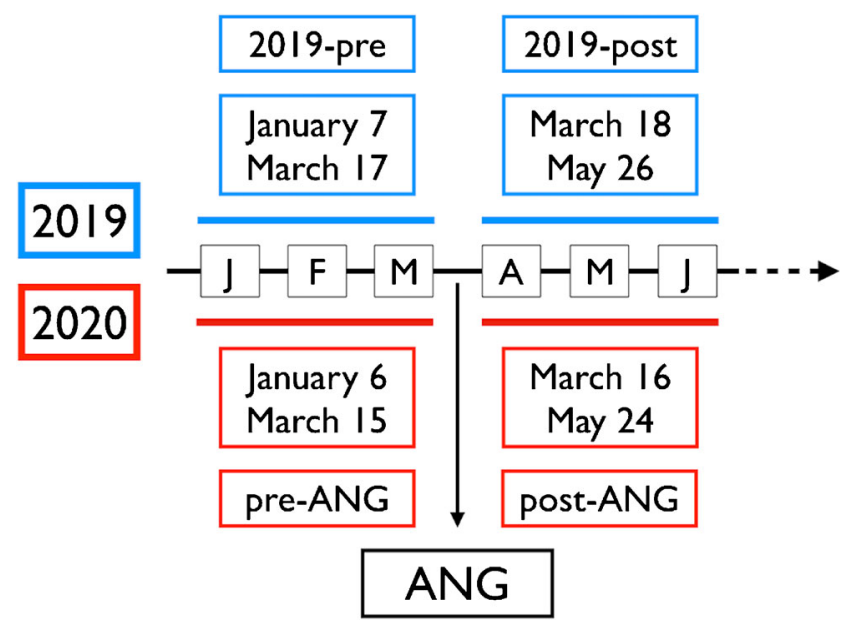

Fig. 1 In 2020, the 10-week intervals before (pre-ANG) and after (postANG) the accomplishment of new guidelines (ANG) for maintaining only essential activities are marked in red. Year 2019 (blue) was used as the control, comparing similar periods of 10 weeks

similar periods of 10 weeks, from January 7 to March 17 and from March 18 to May 26 (Fig. 1).

Statistical analysis was performed using Stata software version 14 . The non-parametric distribution variables were assessed using the Wilcoxon Rank Sum. Differences were considered statistically significant if $p<0.05$ in a $95 \%$ confidence interval.

\section{Results}

A marked reduction of $74.2 \%$ on the total number of procedures was observed in the post-ANG period of 2020. In the comparative 2019-post period, 1036 surgeries were performed (average 103.6 \pm 9.7 per week). Despite the significant reduction in the number of operations, 267 procedures still occurred in the post-ANG period (average 26.7 $\pm 20,3$ per week) ( $p=$ 0.0002 ). Before the pandemic, in the pre-ANG 2020 period, 924 surgical procedures were done (average $92.4 \pm 12.0$ per week), while in the similar 2019 period, 960 surgeries were performed ( $96.0 \pm 19.5$ per week) $(p=0.2260)$ (Fig. 2).

Although there was a reduction in the total number of surgeries, an increase in the proportion of reconstructive in comparison with aesthetic procedures occurred in the post-ANG period, compared with 2019-post. Cosmetic surgeries were reduced from 19.8 to $4.9 \%$, and the proportions of reconstructive procedures increased from 80.2 to $95.1 \%(p=0.0002)$. The proportions of reconstructive and aesthetic procedures did not differ significantly when the pre-ANG and the 2019-pre periods were compared ( $p=0.0813$ ) (Fig. 3). 
Fig. 2 Total number of surgeries performed weekly in the preANG and post-ANG (red) compared with 2019-pre and 2019post (blue). A sudden reduction can be observed after the accomplishment of new guidelines for maintaining only essential activities in 2020

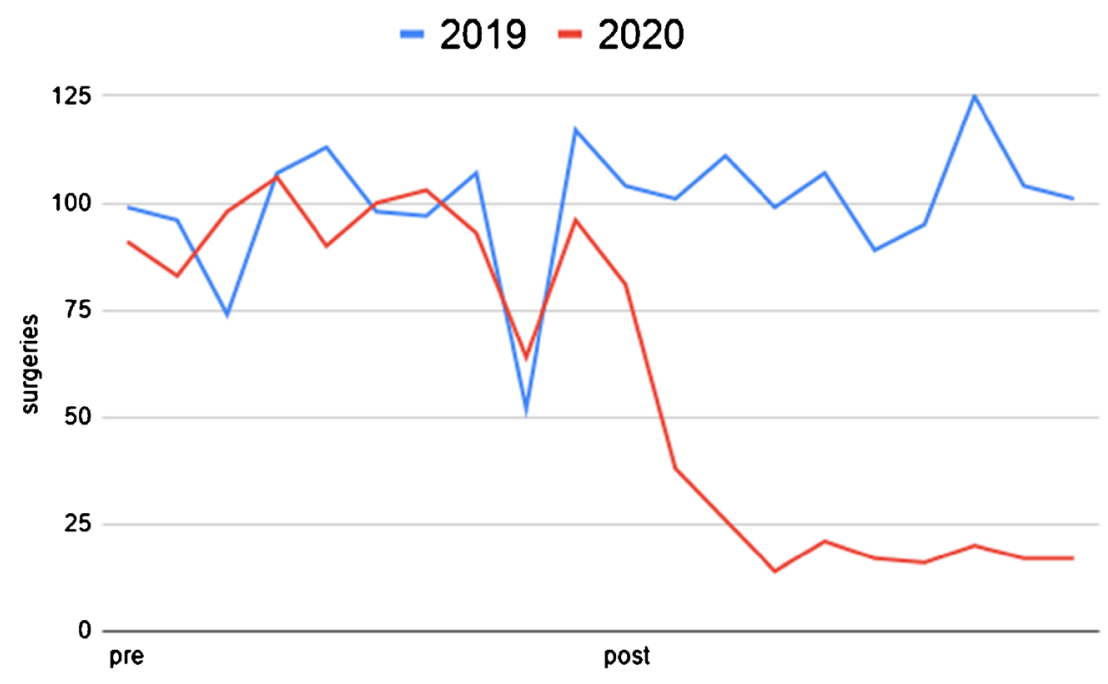

In the first weeks of the pandemic, a universal decrease in procedures was observed. In the high-exposure building, however, a rise in the number of surgeries was progressively noticed (Fig. 4). Pressure injuries and patients transferred from other buildings with confirmed COVID-19 requiring plastic surgery treatment were the leading causes. Since new admissions were sharply reduced for non-COVID patients, the only source of procedures in individuals without confirmed COVID-19 was admissions of trauma at the emergency department (facial fractures and complex wounds) and oncologic patients (Fig. 5).

Regarding the number of outpatient visits, a decrease of $59.8 \%$ was observed after ANG. A total of 1571 consultations were performed $(157.1 \pm 93,6$ per week) in the post-ANG period, while in the 2019-post period, $3907(390.7 \pm 43.1)$ were done $(p=0.0003)$. In the pre-ANG period, 3603 consultations were fulfilled ( $360.3 \pm 107.5$ per week), while in the 2019-pre period, 3723 consultations had been accomplished (372.3 \pm 114.9 per week) $(p=0.4495)$ (Fig. 6).

\section{Discussion}

As a reference center in the Greater São Paulo for fighting against the COVID-19, the HCMFUSP gathered all patients infected with this disease in just one institute, moving all activities not related to COVID-19 to other units of the complex. As a consequence, immediate oncological reconstructions,
Fig. 3 Proportion of aesthetic (red) and reconstructive (blue) surgeries performed at the institution in the 2019-pre, pre-ANG, 2019-post, and post-ANG periods. An increase in the proportion of reconstructive surgeries can be observed after the accomplishment of new guidelines for maintaining only essential activities in 2020

\section{aesthetic reconstructive}

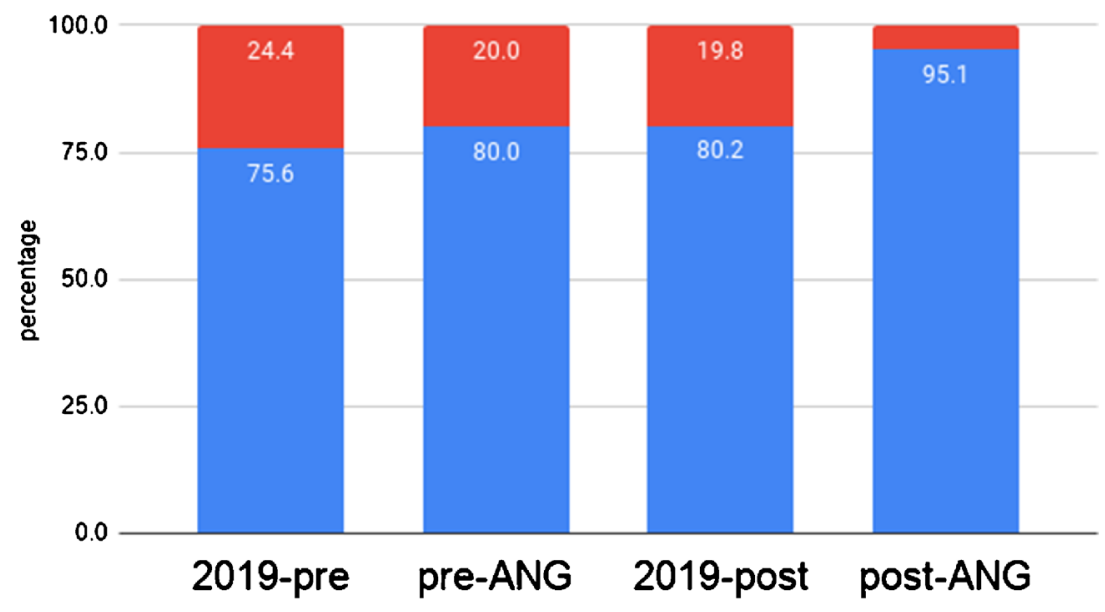


Fig. 4 Number of surgeries performed weekly by the Division of Plastic Surgery at the highexposure institute reserved for the care of patients with COVID-19 (red) and at other low-exposure institutes (blue) in the post-ANG period. There is a progressive increase in the number of surgeries at the high-exposure institute

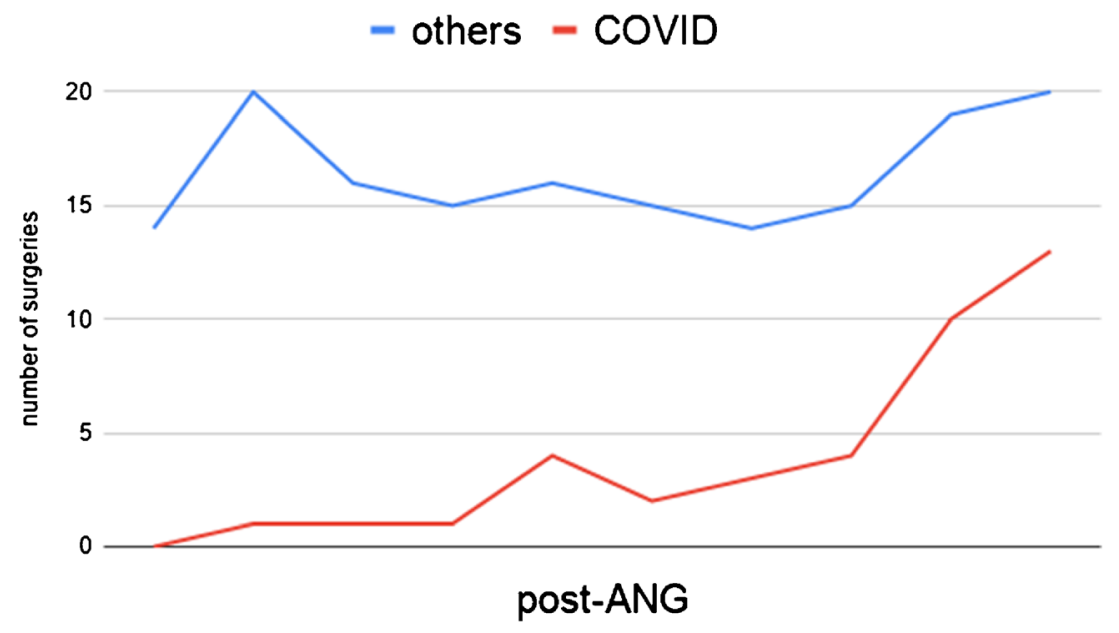

facial trauma surgical treatment, and complex wound care were maintained in these institutes with low exposure to the infectious agent.

Regarding surgeries performed after ANG, a drastic reduction in the total number was observed (Fig. 2), followed by an increase in the proportion of reconstructive procedures (Fig. 3).

Despite the reduction in the absolute number, reconstructive surgeries maintained the usual complexity and provided practical training for residents. Although 739 reconstructive surgeries had been done in the 2019-post period, the 254 reconstructive surgeries performed in the post-ANG period are still a relevant number. Despite this decrease, high-complexity procedures were performed both in low- and high-exposure buildings. Breast cancer, head and neck tumors, soft tissue sarcomas, melanomas, and digestive tract neoplasms were the leading causes for high complexity reconstruction, such as microsurgical flaps. In addition to these reconstructions, other procedures were maintained at low-exposure institutes for the surgical treatment of facial trauma and complex wounds. As HCFMUSP also remained as a reference center for trauma, the severe victims of these injuries maintained their treatments in the low-exposure institutes.

Despite not being a specialty related to the direct care of patients affected by SARS-CoV-2, the Division of Plastic Surgery maintained a fundamental role in the high-exposure institute throughout the pandemic. Initially, the most significant concern and demand were to guarantee medical assistance and intensive care to patients referred to the highexposure institute. However, as acutely critical patients occupied the beds, the demand for the prevention and treatment of wounds related to the medical care of these patients, such as pressure injuries, was noticed (Fig. 5). Patients operated at low-exposure institutes who evolved with COVID-19
Fig. 5 Requests for evaluations for the Plastic Surgery service of patients admitted to the highexposure institute after March 16, 2020 (post-ANG)

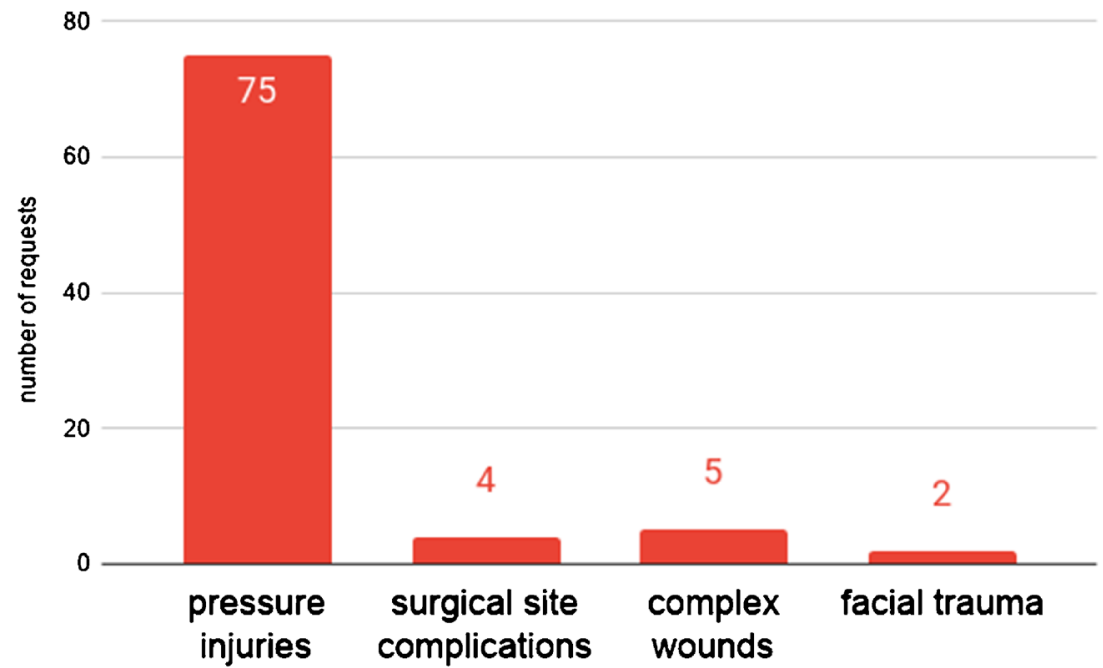


Fig. 6 Total number of outpatient visits performed in 2019-pre and 2019-post periods (blue) and preANG and post-ANG periods (red). A statistically significant reduction can be observed in the post-ANG period compared with the 2019-post

\section{$2019-2020$}

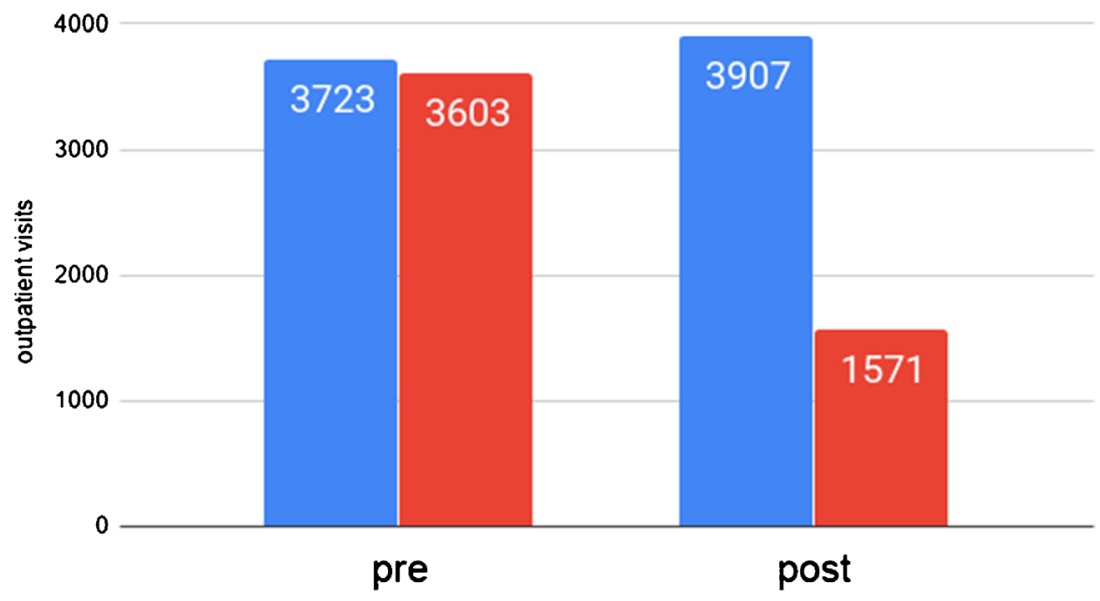

infection and post-operative complications requiring plastic surgery were also treated at the high-exposure institute. Every referral center for trauma or other surgical emergencies should consider the possibility of patients presenting with COVID-19 in the active or incubation phase. Personal protective equipment must be provided for the entire team until the diagnosis can be excluded [9].

Thus, the unit dedicated exclusively to the care of patients affected by COVID-19 also recorded surgical cases, all of them in confirmed COVID-19 patients without the possibility of postponing treatment. Operations were related to the treatment of pressure injuries, complex wounds, and treatment of surgical site complications. Reconstructive surgeries are of high relevance during the pandemic season, due to the demand created by the admission of a large number of acutely critical patients. As shown in Fig. 5, the occurrence of pressure injuries was the leading cause of Plastic Surgery visits at the high-exposure institute. The hypothesis for this more significant occurrence is difficulty in mobilizing patients and the need for pronation to optimize ventilation parameters [10, 11]. Consequently, the plastic surgeon is an essential part of the multidisciplinary team for treating pressure injuries in the supine or prone position, acting directly in the care of these injuries in patients with COVID-19, and guiding the health care professionals in the prevention and treatment of the identified injuries.

\section{Conclusion}

The COVID-19 pandemic has profoundly affected plastic surgery activity worldwide. The prevailing profile of reconstructive surgeries at the Division of Plastic Surgery of HCFMUSP allowed the continuity of procedures at all levels of technical complexity. The employed adaptations ensured the maintenance of patient care and the continuity of Plastic Surgery residency training.

Authors' contributions Vitor Penteado Figueiredo Pagotto: Conceptualization, investigation, project administration, writingoriginal draft preparation. Laielly Abbas: Conceptualization, data curation. Dov Charles Goldenberg: Writing - review and editing. Rodolfo Costa Lobato: Conceptualization, data curation. Bruno Baptista do Nascimento: Conceptualization, data curation. Gustavo Gomes Ribeiro Monteiro: Conceptualization, data curation. Cristina Pires Camargo: Formal analysis, methodology. Fabio de Freitas Busnardo: Supervision. Rolf Gemperli: Supervision, visualization.

Data availability Data sheet available.

\section{Compliance with ethical standards}

Conflict of interest Vitor Penteado Figueiredo Pagotto, Laielly Abbas, Dov Charles Goldenberg, Rodolfo Costa Lobato, Bruno Baptista do Nascimento, Gustavo Gomes Ribeiro Monteiro, Cristina Pires Camargo, Fabio de Freitas Busnardo, and Rolf Gemperli declare no conflict of interest.

Ethics approval This is an observational study. The Institution Research Ethics Committee has confirmed that no ethical approval is required.

Consent to participate Not applicable.

Consent for publication Not applicable.

Informed consent This is an observational study. The Institution Research Ethics Committee has confirmed that no informed consent is required. 


\section{References}

1. Cheng VC, Lau SK, Woo PC, Yuen KY (2007) Severe acute respiratory syndrome coronavirus as an agent of emerging and reemerging infection. Clin Microbiol Rev 20(4):660-694

2. WHO Timeline - COVID-19

3. Painel de casos de doença pelo coronavírus 2019 (COVID-19) no Brasil pelo Ministério da Saúde. https://covid.saude.gov.br/

4. Emplasa, GIP/CDI, 2019. https://emplasa.sp.gov.br/RMSP

5. Plano São Paulo - Secretaria de Saúde - Governo do Estado de São Paulo

6. Comitê de Gestão - COVID-19: Recomendações aos Cirurgiões Plásticos Brasileiros. 16 de Março de 2020. Sociedade Brasileira de Cirurgia Plástica

7. Informativo ${ }^{\circ} 10$ 18/03/2020 - Comitê de Crise do Coronavírus HCMFUSP
8. Lei S, Jiang F, Su W, Chen C, Chen J, Mei W, Zhan LY, Jia Y, Zhang L, Liu D, Xia ZY, Xia Z (2020) Clinical characteristics and outcomes of patients undergoing surgeries during the incubation period of COVID-19 infection. Version 2. EClinical Medicine 21: 100331

9. Brito BL, Isaac C, Neves DP, Giavina-Biachi P (2020) COVID-19: how to manage plastic surgery practice in Brazil. What we know up to now. Rev. Bras. Cir. Plas. 35(2):00-00

10. Nazerali RS, Song KR, Wong MS (2010) Facial pressure ulcer following prone positioning. J Plast Reconstr Aesthet Surg 63(4): e413-e414 Epub 2009 Nov 25

11. Zingarelli EM, Ghiglione M, Pesce M, Orejuela I, Scarrone S, Panizza R (2020) Facial pressure ulcers in a COVID-19 50-yearold female intubated patient. Indian J Plast Surg. 53(1):144-146

Publisher's note Springer Nature remains neutral with regard to jurisdictional claims in published maps and institutional affiliations. 